\title{
Analysis of leakage in IRGA's leaf chambers of open gas exchange systems: quantification and its effects in photosynthesis parameterization
}

\author{
J. Flexas ${ }^{1, \star}$, A. Díaz-Espejo ${ }^{2}$, J. A. Berry ${ }^{3}$, J. Cifre ${ }^{1}$, J. Galmés ${ }^{1}$, R. Kaldenhoff ${ }^{4}$, H. Medrano ${ }^{1}$ and \\ M. Ribas-Carbó ${ }^{1}$ \\ ${ }^{1}$ Laboratori de Fisiologia Vegetal, Grup de Recerca en Biologia de les Plantes en Condicions Mediterrànies, \\ Universitat de les Illes Balears, Carretera de Valldemossa Km 7.5, 07122 Palma de Mallorca, Balears, Spain \\ 2 Instituto de Recursos Naturales y Agrobiología, CSIC, Apartado 1052, 41080 Sevilla, Spain \\ ${ }^{3}$ Carnegie Institution of Washington, Department of Global Change Biology, 260 Panama Street, Stanford, \\ CA 94305, USA \\ ${ }^{4}$ Darmstadt University of Technology, Institute of Botany, Applied Plant Sciences. Schnittspahnstrasse 10, \\ D-64287 Darmstadt, Germany
}

Received 8 December 2006; Revised 22 January 2007; Accepted 23 January 2007

\section{Abstract}

The measurement of the response of net photosynthesis to leaf internal $\mathrm{CO}_{2}$ (i.e. $A-C_{i}$ curves) is widely used for ecophysiological studies. Most studies did not consider $\mathrm{CO}_{2}$ exchange between the chamber and the surrounding air, especially at the two extremes of $A-C_{i}$ curves, where large $\mathrm{CO}_{2}$ gradients are created, leading to erroneous estimations of $A$ and $C_{i}$. A quantitative analysis of $\mathrm{CO}_{2}$ leakage in the chamber of a portable open gas exchange system (Li-6400, LI-COR Inc., NE, USA) was performed. In an empty chamber, the measured $\mathrm{CO}_{2}$ leakage was similar to that calculated using the manufacturer's equations. However, in the presence of a photosynthetically inactive leaf, the magnitude of leakage was substantially decreased, although still significant. These results, together with the analysis of the effects of chamber size, tightness, flow rate, and gasket material, suggest that the leakage is larger at the interface between the gaskets than through the gaskets. This differential leakage rate affects the parameterization by photosynthesis models. The magnitude of these errors was assessed in tobacco plants. The results showed that leakage results in a $10 \%$ overestimation of the leaf maximum capacity for carboxylation $\left(V_{c, \text { max }}\right)$ and a $40 \%$ overestimation of day respiration $\left(R_{1}\right)$. Using the manufac-
\end{abstract}

turer's equations resulted in larger, non-realistic corrections of the true values. The photosynthetic response to $\mathrm{CO}_{2}$ concentrations at the chloroplast (i.e. $A-C_{c}$ curves) was significantly less affected by leakage than $A-C_{i}$ curves. Therefore, photosynthetic parameterization can be improved by: (i) correcting $A$ and $C_{i}$ values for chamber leakage estimated using a photosynthetically inactive leaf; and (ii) using $A-C_{c}$ instead of $A-C_{i}$ curves.

Key words: Gas exchange, leakage, measurement errors, photosynthesis parameterization.

\section{Introduction}

Since the introduction of the photosynthesis model by Farquhar et al. (1980), gas exchange measurements and, particularly, the response of net photosynthesis $(A)$ to substomatal $\mathrm{CO}_{2}$ concentration $\left(\mathrm{C}_{\mathrm{i}}\right)$, i.e. the $A-\mathrm{C}_{\mathrm{i}}$ curve, have been widely used to parameterize leaf photosynthesis. The analysis of $A-C_{\mathrm{i}}$ curves allows the determination of rates of carboxylation, ribulose bisphosphate (RuBP) regeneration, or triose phosphate export out of the chloroplast, as well as quantification of the maximum carboxylation capacity $\left(V_{\mathrm{c}, \max _{\mathrm{Ci}}}\right)$, the maximum capacity for electron transport rate $\left(J_{\text {max }_{-} \mathrm{Ci}}\right)$, and the velocity for

* To whom correspondence should be addressed. E-mail: jaume.flexas@uib.es 
triose phosphate utilization $\left(V_{\mathrm{TPU} \_\mathrm{Ci}}\right)$. These analyses have proven to be useful to develop prediction models of $\mathrm{CO}_{2}$ assimilation for crops (Díaz-Espejo et al., 2006) and natural vegetation ( $\mathrm{Xu}$ and Baldocchi, 2003), to help predict the effects of climate change on photosynthesis (Sabaté et al., 2002), as a solid physiological basis for scaling up from leaf to whole plant and/or ecosystem carbon assimilation models (Woodward et al., 1995), and to assess the influence of several stresses, such as drought (Wilson et al., 2000), salinity (Centritto et al., 2003), extreme temperatures (Zhou et al., 2004), light constraints (Schultz, 2003), nutrient deficiency (Warren, 2004), or biotic stress (Sampol et al., 2003) on the photosynthetic capacity.

The importance and versatility of $A-\mathrm{C}_{\mathrm{i}}$ curves for ecophysiological studies have raised debates on the technical aspects of their performance together with the technical limitations presented by the commercial instruments developed for their analysis (Long and Hällgren, 1993; Long and Bernacchi, 2003). Moreover, the introduction of combined gas exchange with isotope discrimination and/or with chlorophyll fluorescence analysis has allowed the estimation of leaf mesophyll conductance to $\mathrm{CO}_{2}\left(\mathrm{~g}_{\mathrm{m}}\right)$ and the chloroplastic $\mathrm{CO}_{2}$ concentration $\left(\mathrm{C}_{\mathrm{c}}\right)$, which often differs from $\mathrm{C}_{\mathrm{i}}$ as much as this differs from the atmospheric $\left(\mathrm{C}_{\mathrm{a}}\right) \mathrm{CO}_{2}$ concentration (Evans et al., 1986; Harley et al., 1992; Loreto et al., 1992). Because the model of Farquhar et al. (1980) is based on the assumption that the $A-\mathrm{C}_{\mathrm{i}}$ curve can be mostly assimilated to Michaelis-Menten kinetics (i.e. as $A$ being the velocity of an enzyme-mediated reaction and $C_{i}$ being the substrate concentration at the site of the enzyme), the fact that $C_{i}$ and $\mathrm{C}_{\mathrm{c}}$ substantially differ has pointed to the convenience of taking into account $\mathrm{g}_{\mathrm{m}}$ in the parameterization of $A-\mathrm{C}_{\mathrm{i}}$ curves (Bernacchi et al., 2002; Ethier and Livingston, 2004) or to convert them to $A-\mathrm{C}_{\mathrm{c}}$ curves prior to assessing actual $V_{\text {c_max }}$ and $J_{\max }$ (Flexas et al., 2002, 2004; Terashima and Ono, 2002; Manter and Kerrigan, 2004; Warren et al., 2004; Galmés et al. 2006).

Several limitations of $A-\mathrm{C}_{\mathrm{i}}$ curve analysis have been described (Long and Bernacchi, 2003; Galmés et al., 2006). For instance, under some conditions, water stress or feeding abscisic acid induces a heterogeneous closure of stomata (patchiness), which invalidates the estimations of $\mathrm{C}_{\mathrm{i}}$ and, thus, the interpretation of $A-\mathrm{C}_{\mathrm{i}}$ curves (Terashima, 1992; Buckley et al., 1997). Moreover, when stomatal conductance is very low, the influence of cuticular conductance may impair the estimation of $\mathrm{C}_{\mathrm{i}}$ using the typical procedures (Boyer et al., 1997; Flexas et al., 2002). In addition to these limitations, inherent to the stomatal behaviour and the basic formulation of photosynthesis models, other limitations related to the design of the most commercially available gas exchange systems have also been described. For instance, because leaf chambers usually enclose a small leaf surface $\left(2-6 \mathrm{~cm}^{2}\right)$ surrounded by gaskets of a certain width, the illuminated photosynthesizing leaf area is always surrounded by an area darkened by gaskets, which respires and thus affects the measurement of the photosynthetic flux. The effects of this so-called 'edge' effect on respiration and photosynthesis rates have been quantified in detail (Jahnke and Krewitt, 2002; Pons and Welschen, 2002). Also, significant errors in the estimation of stomatal conductance, and subsequently in $\mathrm{C}_{\mathrm{i}}$, have been associated with errors in the measurement of leaf temperature (Tyree and Wilmot, 1990; Verhoef, 1997). Stomatal conductance can be overestimated by $20-60 \%$, especially when $\mathrm{g}_{\mathrm{s}}$ values are low, as under stress conditions.

In addition, it has long been known but practically ignored that some $\mathrm{CO}_{2}$ could escape from or enter the chamber through the leaf gaskets (Long and Hällgren, 1993). This is especially important at the two ends of $A-$ $\mathrm{C}_{\mathrm{i}}$ curves when large $\mathrm{CO}_{2}$ gradients between the chamber and the surrounding air are created. Many recent studies are still using $A-\mathrm{C}_{\mathrm{i}}$ curve analysis without taking the possible effects of leaks into account (Centritto et al., 2003; Bota et al., 2004; Warren et al., 2004; Zhou et al., 2004). Others, as recommended by some manufacturers, correct net photosynthesis values after measuring the apparent photosynthetic fluxes in the absence of a leaf, i.e. with an empty chamber (Bernacchi et al., 2001, 2002; Manter and Kerrigan, 2004; Li-COR, 2005). However, to the best of our knowledge, no detailed analyses of the occurrence and magnitude of gasket leakage under different conditions has been published. The effects of gasket leakage on photosynthesis parameterization using the Farquhar et al. (1980) model are largely unknown, as are its possible effects on $A-\mathrm{C}_{\mathrm{c}}$ curves. On the other hand, it has been recognized that, when a leaf is placed in the chamber, additional leaks may occur that cannot be quantified by measuring fluxes on an empty chamber (Long and Bernacchi, 2003). Therefore, the objectives of the present study are: (i) to quantify the magnitude of leakage in the IRGA's chambers under different conditions; (ii) to compare the magnitude of these leaks with an empty chamber or with a chamber filled with leaves; and (iii) to quantify the effects of such leaks on the parameterization of both $A-\mathrm{C}_{\mathrm{i}}$ and $A-\mathrm{C}_{\mathrm{c}}$ curves performed in transgenic tobacco lines differing in photosynthesis.

\section{Materials and methods}

\section{Plant material}

Tobacco (Nicotiana tabacum L.), grapevine rootstock (R-110, Vitis berlandieri $\times$ rupestris), and cucumber (Cucumis sativus) plants were used for the experiments. Four different lines of transformed tobacco plants differing in the expression of aquaporin NtAQP1, as described by Siefritz et al. (2002) and Uehlein et al. (2003), were used. These plants were chosen because, having an identical leaf structure, they constitutively show large differences in their $A-C_{i}$ 
response curve (Flexas et al., 2006). Because leaf structure and morphology may alter the magnitude of leaks (Long and Bernacchi, 2003), these plants are an ideal material allowing an analysis of the leakage effect using a single kind of leaf structure but at different photosynthetic capacities and without inducing any stress, which may result in patchy stomata closure and preclude a correct analysis of the $A-\mathrm{C}_{\mathrm{i}}$ curves (Terashima, 1992; Buckley et al., 1997).

Antisense (AS) and overexpressing plants (O) were obtained from different lines: var. Samsun for AS and Hö 20.20 for O. Nontransformed plants of each line were used as controls (CAS and $\mathrm{CO}$ ). AS lines were constitutive, whereas in O the NtAQP1 coding region was under the control of a tetracycline-inducible promoter (Uehlein et al., 2003). The plants were grown as described (Flexas et al., 2006).

\section{Gas exchange and chlorophyll fluorescence measurements}

Leaf gas exchange was determined simultaneously with measurements of chlorophyll fluorescence using the open gas exchange system Li-6400 (LI-COR Inc., Lincoln, NE, USA) with an integrated fluorescence chamber head (Li-6400-40; LI-COR Inc.). Unless stated, white gaskets were used in the leaf chamber. Measurements were made on the youngest fully expanded leaf. The actual photochemical efficiency of photosystem II $\left(\phi_{\text {PSII }}\right)$ was determined by measuring steady-state fluorescence $\left(F_{\mathrm{s}}\right)$ and maximum fluorescence during a light-saturating pulse of $\sim 8000 \mu \mathrm{mol}$ $\mathrm{m}^{-2} \mathrm{~s}^{-1}\left(F_{\mathrm{m}}^{\prime}\right)$ following the procedures of Genty et al. (1989):

$$
\phi_{\text {PSII }}=\left(F_{\mathrm{m}}^{\prime}-F_{\mathrm{s}}\right) / F_{\mathrm{m}}^{\prime}
$$

The electron transport rate $(J)$ was then calculated as:

$$
\mathrm{J}=\phi_{\mathrm{PSII}} \cdot \mathrm{PPFD} \cdot \alpha
$$

where PPFD is the photosynthetic photon flux density and $\alpha$ is a term which includes the product of leaf absorptance and the partitioning of absorbed quanta between photosystems I and II. $\alpha$ was previously determined as the slope of the relationship between $\phi_{\mathrm{PSII}}$ and $\phi_{\mathrm{CO}_{2}}$ obtained by varying light intensity under nonphotorespiratory conditions in an atmosphere containing $<1 \% \quad \mathrm{O}_{2}$ (Valentini et al., 1995).

In light-adapted leaves, photosynthesis was induced with saturating light $\left(1000 \mu \mathrm{mol} \mathrm{m}^{-2} \mathrm{~s}^{-1}\right)$ and $400 \mu \mathrm{mol} \mathrm{mol}^{-1} \mathrm{CO}_{2}$ surrounding the leaf $\left(\mathrm{C}_{\mathrm{a}}\right)$ with $15 \%$ blue light to maximize stomatal aperture. Leaf temperature was maintained at $25^{\circ} \mathrm{C}$, and leaf-to-air vapour pressure deficit was kept between $1 \mathrm{kPa}$ and $2 \mathrm{kPa}$ in all measurements. $\mathrm{CO}_{2}$ response curves were performed at steady state, at least $30 \mathrm{~min}$ after clamping the leaf. Six $\mathrm{CO}_{2}$ response curves were obtained for each plant line. Gas exchange and chlorophyll fluorescence were first measured at $400 \mu \mathrm{mol} \mathrm{mol}^{-1}$, then $\mathrm{C}_{\mathrm{a}}$ was increased stepwise up to $1800 \mu \mathrm{mol} \mathrm{mol} \mathrm{m}^{-1}$ and returned to its original value, followed by a stepwise decrease down to $0 \mu \mathrm{mol}$ mol $^{-1}$. A was measured at 12 different $\mathrm{C}_{\mathrm{a}}$ values for each curve.

The chloroplastic $\mathrm{CO}_{2}$ concentration $\left(\mathrm{C}_{\mathrm{c}}\right)$ was estimated from combined gas exchange and chlorophyll fluorescence according to Epron et al. (1995) as:

$$
\mathrm{C}_{\mathrm{c}}=(O / S) \cdot\left\{\left[J+8 \cdot\left(A+R_{1}\right)\right] /(2 \cdot \mathrm{J})-8 \cdot\left(A+R_{1}\right)\right\}
$$

where $\mathrm{O}$ is the $\mathrm{O}_{2}$ concentration in the chloroplast (assumed $0.21 \mathrm{~mol} \mathrm{~mol}^{-1}$ ), $S$ is the specificity factor of Rubisco, and $R_{1}$ is the rate of mitochondrial respiration in the light. Due to the difficulties of obtaining reliable $R_{1}$ values with the most commonly used methods (Galmés et al., 2006; and see Results), dark respiration $\left(R_{\mathrm{D}}\right)$ was taken as a proxy for $R_{\mathrm{L}}$, following Pinelli and Loreto (2003). A value of $S$ of $2459 \mathrm{~mol} \mathrm{~mol}^{-1}$, corresponding to a $\mathrm{CO}_{2}$ compensation point in the absence of respiration $\left(\Gamma^{*}\right)$ of $42.75 \mu \mathrm{mol} \mathrm{mol}{ }^{-1}$, was taken after Bernacchi et al. (2001). The estimated $\mathrm{C}_{\mathrm{c}}$ values were used to convert $A-\mathrm{C}_{\mathrm{i}}$ curves into $A-\mathrm{C}_{\mathrm{c}}$ curves (Terashima and Ono, 2002; Manter and Kerrigan, 2004).

From $A-\mathrm{C}_{\mathrm{i}}$ curves, the following photosynthetic parameters were calculated according to Long and Bernacchi (2003): mitochondrial respiration in the light $\left(R_{1}\right)$, maximum carboxylation capacity $\left(V_{\mathrm{c}, \text { max_Ci }}\right)$, maximum capacity for electron transport rate $\left(J_{\text {max_Ci }}\right)$, and the velocity for triose phosphate utilization $\left(V_{\mathrm{TPU}} \mathrm{Ci}\right)$. From $A-$ $\mathrm{C}_{\mathrm{c}}$ curves, only the maximum carboxylation capacity $\left(V_{\mathrm{c}, \text { max_Cc }}\right)$ and the maximum capacity for electron transport rate $\left(J_{\text {max }_{-} C c}\right)$ were calculable (Manter and Kerrigan, 2004). The temperature dependence of kinetic parameters of Rubisco for $A-\mathrm{C}_{\mathrm{c}}$ curves was calculated following Bernacchi et al. (2002).

\section{Leakage analysis}

In order to establish the magnitude of gasket leakage, $\mathrm{CO}_{2}$ response curves using an empty chamber were run under different conditions. These curves were performed using two different chamber sizes, a $6 \mathrm{~cm}^{2}(6400-02 \mathrm{~B})$ and a $2 \mathrm{~cm}^{2}(6400-40)$ chamber. Additionally, two types of chamber gaskets, the white (spare part number 640030) and black (spare part number 6400-33) gaskets, were compared. Finally, different tightness of the chamber closure and different flow rates were compared.

Several methods attempting to minimize the magnitude of leakage were tested: (i) painting the entire external and internal surfaces of the gaskets with nail varnish; (ii) enclosing the entire chamber head in a plastic bag; and (iii) surrounding the chamber gaskets with a perforated tube ring connected to the exhaust of a second Li-6400 running an identical $\mathrm{CO}_{2}$ response curve in parallel.

Leakage of an empty chamber and of a chamber filled with an inert tobacco leaf was compared. To avoid large changes in leaf structure, leaves were thermally killed by immersion in boiling water until no variable chlorophyll fluorescence was detectable (typically a few minutes after boiling was started) measured using a PAM-2000 (Walz, Effeltrich, Germany), which was taken as evidence for total photosynthesis impairment and leaf death (Schreiber et al., 1998). While there was some unavoidable turgor loss in the heated leaf, it was obviously not as much as in the dried leaf used by Long and Bernacchi (2003). The general aspect and thickness of the boiled leaf resembled more those of a living leaf rather than of a dried leaf or a piece of paper.

The actual $A$ values of living leaves were corrected by simple subtraction of the relationship between $\mathrm{C}_{\mathrm{a}}$ and the 'apparent' photosynthesis of either an empty chamber or a chamber filled with a dead leaf. $C_{i}$ and $C_{c}$ values were then recalculated using the manufacturer's formulae.

\section{Statistical analysis}

One-way analysis of variance (ANOVA) was applied to assess the differences for each parameter between each separate control and its derivate line. Differences among means were established using a Duncan test $(P<0.1)$. The data were analysed applying the SPSS 10.0 program for Windows.

\section{Results and Discussion}

\section{Magnitude of leakage through the gaskets of an empty chamber under different conditions}

The magnitude of $\mathrm{CO}_{2}$ leakage in the IRGA chamber was determined from several $A-\mathrm{C}_{\mathrm{i}}$ curves with an empty chamber. Linear relationships between 'apparent' net 
photosynthesis and $\mathrm{C}_{\mathrm{a}}$ were obtained (Fig. 1A). Applying the manufacturer's equation to determine the diffusion coefficient $k$ resulted in a $k$ of about 0.44 , which is very close to the value of 0.46 provided by the manufacturer (Li-COR, 2005). However, contrary to the manufacturer's suggestions (Li-COR, 2005), there were no differences between the round $2 \mathrm{~cm}^{2}$ chamber and the rectangular $6 \mathrm{~cm}^{2}$ chamber, as both yielded similar relationships for a given set-up (data not shown). Changes in flow rate had a relatively minor effect on the magnitude of leakage (Fig. 1B). Also, in contrast to the manufacturer's suggestions that leakage is detectable only at low flow rates $(\mathrm{Li}-\mathrm{COR}$, 2005), leakage was measurable at all flow rates, including a high flow rate of $700 \mu \mathrm{mol} \mathrm{s}{ }^{-1}$.

The effect of tightness of the chamber on the leakage was tested by performing $A-C_{\mathrm{i}}$ curves in an empty chamber at four different levels of tightness (initial, 1/4, $3 / 4$, and a full turn of the nut). The tightness of closure did not significantly affect the magnitude of leakage (Fig. 1C). Therefore, reducing the gasket surface exposed to the interface between the inside and outside of the chamber did not significantly affect leakage. The magnitude of leakage through two different types of gaskets provided by LI-COR (spare part numbers 6400-30 and 6400-33) was also tested (Fig. 1D). Although black neoprene gaskets have a lower diffusivity to $\mathrm{CO}_{2}$ than the white gaskets (Li-COR, 2005), the magnitude of leakage was much larger when using the former (Fig. 1D). These results strongly suggest that most chamber leakage occurs between the two sealing gaskets and not through the gasket itself. Some researchers use grease to improve the seal between the leaf and the gasket which, in view of the results, may be a good way to reduce leakage.

\section{Attempts to eliminate or minimize leakage}

Several methods to avoid or reduce leakage were tested. These methods included (i) painting the entire external and internal surfaces of the gaskets with nail varnish; (ii) enclosing the entire chamber head in a plastic bag; and (iii) surrounding the chamber gaskets with a tube ring supplying external air to the vicinity of the gaskets with a $\mathrm{CO}_{2}$ concentration identical to the internal one. Painting the surfaces of gaskets with nail varnish-which is known to be largely impermeable to air-did not modify the magnitude of the leakage (data not shown), supporting the

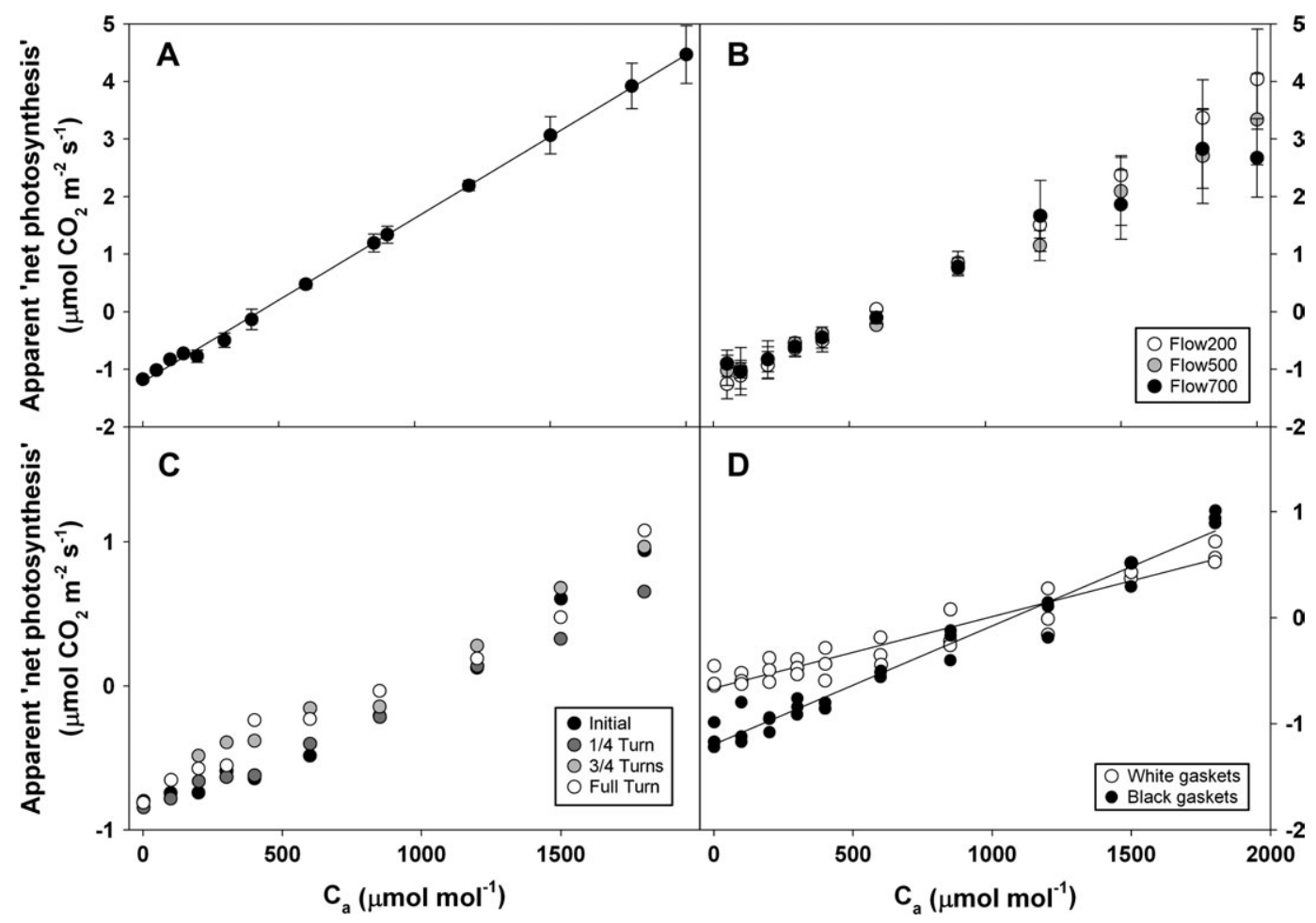

Fig. 1. (A) The response of leakage flow ('apparent net photosynthesis') to $\mathrm{CO}_{2}$ concentration $\left(\mathrm{C}_{\mathrm{a}}\right)$ in the empty $2 \mathrm{~cm}^{2}$ chamber. Values are the average \pm SE of three replicate curves. (B) The effect of flow rate through IRGA's circuit on leakage. Three different flow rates were applied under identical conditions, using the empty chamber: 200,500 , and $700 \mu \mathrm{mol} \mathrm{s}{ }^{-1}$. Values are the average \pm SE of three replicate curves. (C) The effect of chamber closure tightness on leakage (empty chamber). Filled circles represent the lowest closure tightness initially set up. Dark grey circles are data with the chamber 1/4 turn tighter, light grey 3/4, and open circles an entire turn tighter. A single representative curve is shown for each situation. (D) The response of leakage flow ('apparent net photosynthesis') to $\mathrm{CO}_{2}$ concentration $\left(\mathrm{C}_{\mathrm{a}}\right)$ in the empty $2 \mathrm{~cm}^{2}$ chamber using the white and black gaskets. Three replicate curves are shown with each type of gasket. 
idea that most leakage occurs between the two gaskets. The effects of surrounding the gaskets with a $\mathrm{CO}_{2}$ flushing ring, or enclosing, in addition, the chamber in a plastic bag, are shown in Fig. 2. These manipulations contributed to reduce the magnitude of the leaks, so that the maximum reduction was achieved when combining chamber enclosure in a plastic bag with $\mathrm{CO}_{2}$ flushing surrounding the gaskets (Fig. 2). Even so, a large part of the total leakage $(\sim 80 \%)$ remained even when taking these precautions, which suggests that these methods do not fully eliminate leaks. There could be several reasons for this. First, the typical time course of an $A-\mathrm{C}_{\mathrm{i}}$ curve (i.e. a few minutes between each change in $\mathrm{CO}_{2}$ concentration), as used here, may not be sufficient to allow total equilibration between the $\mathrm{CO}_{2}$ concentrations outside and inside the chamber, particularly when a large bag (i.e. a large air volume) is used. Secondly, air pressure inside the chamber is always a bit higher than that outside to avoid $\mathrm{CO}_{2}$ entry, and therefore some leakage towards the outside may be unavoidable (Li-COR, 2005; Jahnke and Pieruschka, 2006). To achieve a perfect seal is quite difficult and would be even more difficult when measuring a living attached leaf. On the other hand, $\mathrm{CO}_{2}$ flushing around the gaskets also seems insufficient, not to mention the fact that the option of having the use of two IRGAs at the same time is not available to most researchers. Therefore, the proposed methods to minimize IRGA's chamber leakage do not seem a promising tool for the correct measurement of $A-\mathrm{C}_{\mathrm{i}}$ curves; therefore, it must be concluded that it would be necessary to estimate them correctly and use such estimates to correct $A-\mathrm{C}_{\mathrm{i}}$ data.

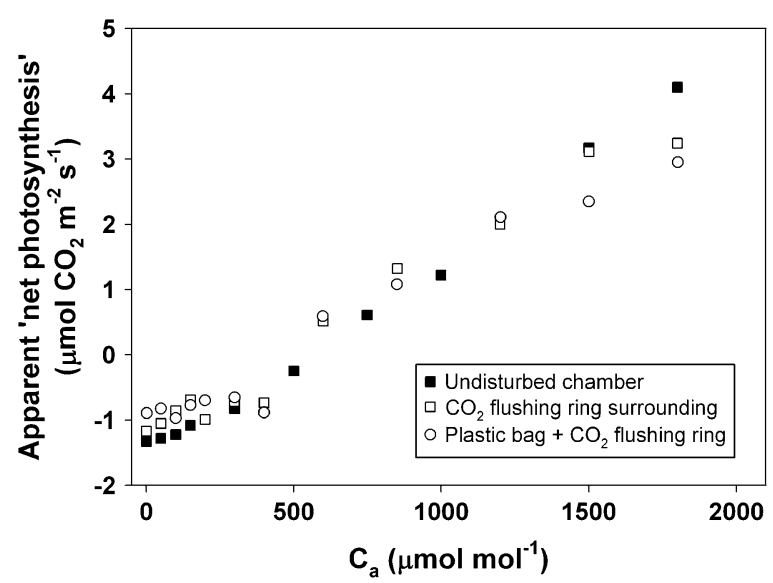

Fig. 2. The response of leakage flow ('apparent net photosynthesis') to $\mathrm{CO}_{2}$ concentration $\left(\mathrm{C}_{\mathrm{a}}\right)$ in the empty $2 \mathrm{~cm}^{2}$ chamber (black squares), by externally flushing air surrounding the gaskets with the same $\mathrm{CO}_{2}$ concentration as in the inside (white squares), or by both enclosing the chamber in a plastic bag and flushing $\mathrm{CO}_{2}$ (white circles). A single representative curve is shown for each situation. Note: for this particular experiment, room $\mathrm{CO}_{2}$ concentration was about $500 \mu \mathrm{mol} \mathrm{mol}^{-1}$.

\section{Comparison of leakage from empty chambers and chambers filled with dead leaves}

Because the magnitude of leakage was seemingly important, and the attempts to minimize it largely failed, it may seem that the most convenient way of performing $A-C_{i}$ studies would be to quantify the magnitude of leakage in each condition, and then correct the resulting $A-\mathrm{C}_{\mathrm{i}}$ curves accordingly, as previously suggested (Bernacchi et al., 2002; Long and Bernacchi, 2003).

However, when a leaf is placed in the chamber, the extent of leakage may differ from that in an empty chamber particularly if, as the above data suggest, most leakage occurs at the interface between the two sealing gaskets, where leaves are placed. Therefore, it must be necessary to obtain photosynthetically inert leaves and insert them in the chamber to quantify the leaks that may occur when measuring a living leaf. Long and Bernacchi (2003) recommend the use of a dead leaf obtained by rapidly drying a live specimen. However, drying may result in loss of some $80 \%$ mass and, thus, in important changes of leaf thickness. The overall structure of a leaf killed by this method may not be very comparable with that of an intact living leaf, therefore interfering with the interpretation of leakage. To avoid large changes in leaf structure, it was decided to kill a leaf thermally by submersing it in boiling water. Using this procedure, less water was lost from the leaf as compared with if it was dried, and the appearance of the dead leaf was much closer to that of a living one. The leaf was submersed in boiling water until no variable chlorophyll fluorescence was detectable (typically a few minutes after initiating boiling), which was taken as evidence for total photosynthesis impairment and leaf death.

Using this procedure, the magnitude of leakage in photosynthetically inactive leaves of $V$. berlandieri $\times$ rupestris, $C$. sativus, and $N$. tabacum was analysed (Fig. 3). In contast to what was previously suggested (Long and Bernacchi, 2003), the magnitude of leakage was much lower when a leaf was inside the chamber than when using an empty chamber, regardless of the species analysed. These results largely reinforce the idea that leakage occurs between the two gaskets. If so, a leaf in the middle of the gaskets would increase the diffusion resistance of the system due to surface rugosity, while differences in leak rates between species (Fig. 3) could perhaps be interpreted as differences in leaf rugosity. Although the magnitude of leakage was reduced in the presence of a dead leaf, it was still significant. Moreover, the fact that the magnitude of leaks differs greatly among different leaves suggests that, in order to improve the accuracy and significance of $A-C_{\mathrm{i}}$ analysis, it would be important to estimate the extent of leakage for any particular species under any given condition, i.e. for any particular experimental conditions. The fact that leakage 


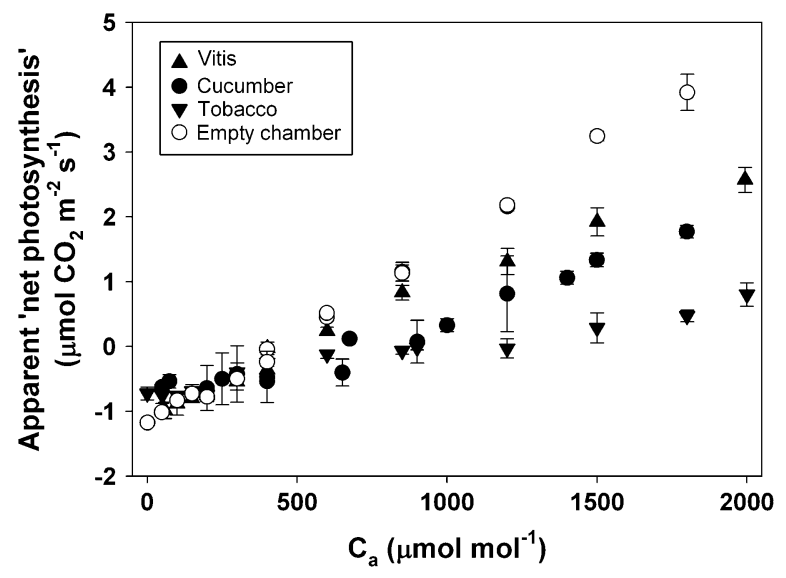

Fig. 3. Comparison of leakage flow ('apparent net photosynthesis') with $\mathrm{CO}_{2}$ concentration $\left(\mathrm{C}_{\mathrm{a}}\right)$ in the empty $2 \mathrm{~cm}^{2}$ chamber (open circles) and the chamber filled with thermally killed leaves of $V$. berlandieri $\times$ rupestris (filled upright triangles), C. sativus (filled circles), and $N$. tabaccum (filled inverted triangles).

was larger in a heterobaric species such as Vitis than in homobaric tobacco suggests that leakage between the leaf and gasket surfaces is much larger than possible leakage through the leaf mesophyll (Jahnke and Krewitt, 2002; Pieruschka et al., 2005).

Due to large differences in the magnitude of leakage in empty chambers as compared with chambers filled with a photosynthetically inactive leaf, using either basis for correction of true $A$ and $\mathrm{C}_{\mathrm{i}}$ values may yield different results. This is illustrated in Fig. 4 for a tobacco leaf. An $A-\mathrm{C}_{\mathrm{i}}$ curve was performed, and the values were either not corrected, corrected using the manufacturer's diffusion coefficient $k$ of 0.46 , corrected using 'apparent photosynthesis' of the empty chamber, or corrected using 'apparent photosynthesis' of a boiled leaf. Clearly, all the corrections have some effect on $A$ and $\mathrm{C}_{\mathrm{i}}$ values. The corrections either using 'apparent photosynthesis' of the empty chamber or directly using the manufacturer's diffusion coefficient yielded similar results. The corrected photosynthesis differed greatly from uncorrected values, particularly at high $\mathrm{CO}_{2}$ concentrations (Fig. 4A). However, photosynthesis corrected using 'apparent photosynthesis' of the boiled leaf was not so different from uncorrected rates. Hence, using the manufacturer's corrections may suggest that leakage results in errors of $\pm 10 \%$ in the estimations of $A$, depending on $\mathrm{C}_{\mathrm{i}}$, but using a photosynthetically inactive leaf reveals that the errors are only of approximately $\pm 2 \%$ (Fig. 4B).

\section{Leakage effects on photosynthesis parameterization from $A-C_{i}$ curves}

Although the magnitude of leakage was lower when clamping a leaf than when using an empty closed chamber, it was still significant and differed among species. Therefore, an attempt was made to investigate
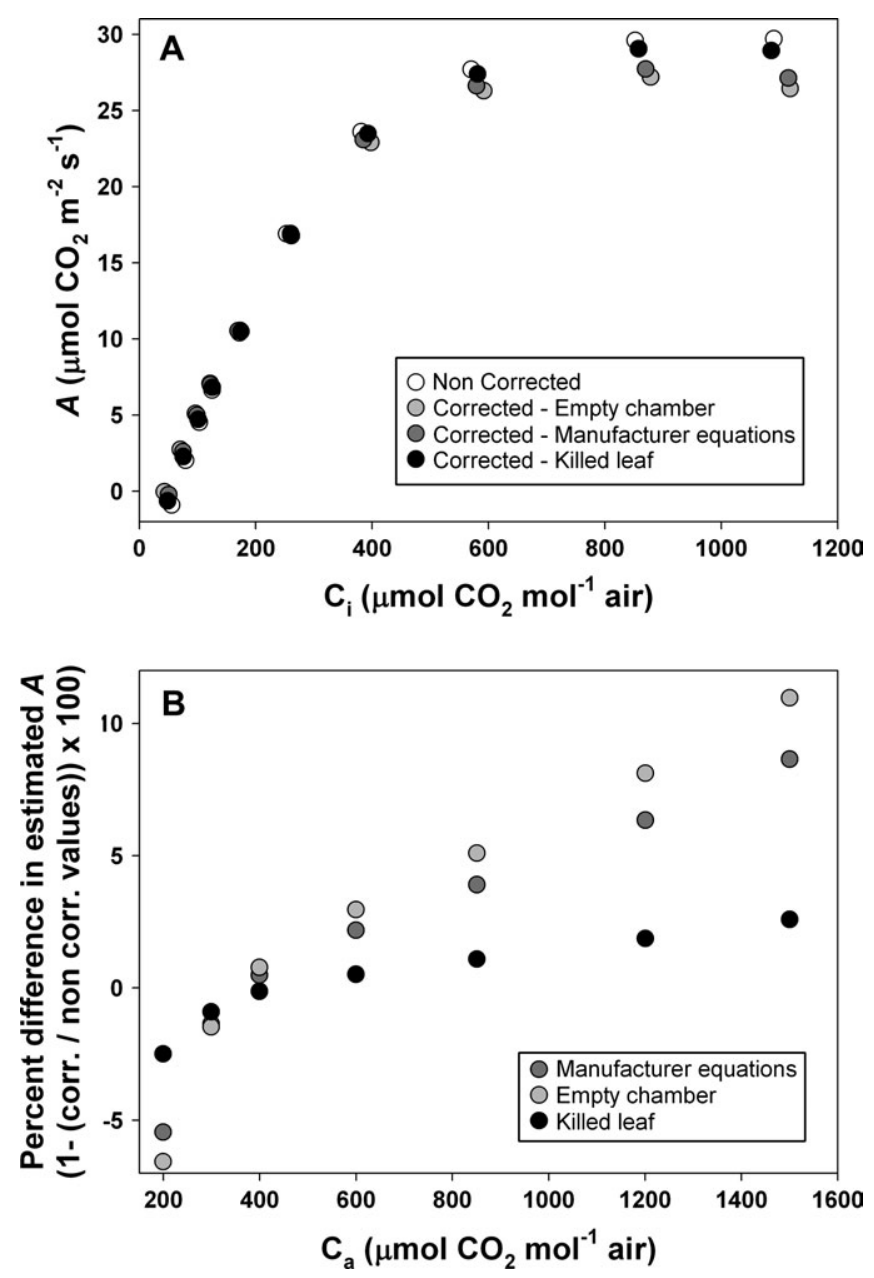

Fig. 4. (A) The response of $A$ to substomatal $\mathrm{CO}_{2}$ concentration, $\mathrm{C}_{\mathrm{i}}$, in a CAS plant of $N$. tabaccum, without correction (open circles) or after correction for leaks obtained with an empty chamber (pale grey circles), the manufacturer's equation with $k=0.46$ (dark grey circles), or leaks obtained with a dead leaf (filled circles). (B) Percentage difference in the estimated $A_{\mathrm{N}}$ when using the different corrections as compared with non-corrected values.

the effects of such leakage on photosynthesis parameterization using the model of Farquhar et al. (1980). Transformed tobacco plants differing in the expression of aquaporin NtAQP1 were chosen for the analysis because, having an identical leaf structure, they constitutively show large differences in their net assimilation rates and $A-\mathrm{C}_{\mathrm{i}}$ response curve (Flexas et al., 2006). The $A-C_{\mathrm{i}}$ curves for the four tobacco lines were either not corrected for leakage, corrected for the leakage estimated using the empty chamber, or corrected for the leakage estimated using a photosynthetically inactive tobacco leaf (Fig. 5). Although differences may be apparent but not large, significant differences appeared in some parameters (Table 1) when photosynthesis was parameterized following Long and Bernacchi (2003).

Day respiration $\left(R_{1}\right)$ was the most strongly affected (by up to $40 \%$ ), suggesting that it may be difficult to estimate 

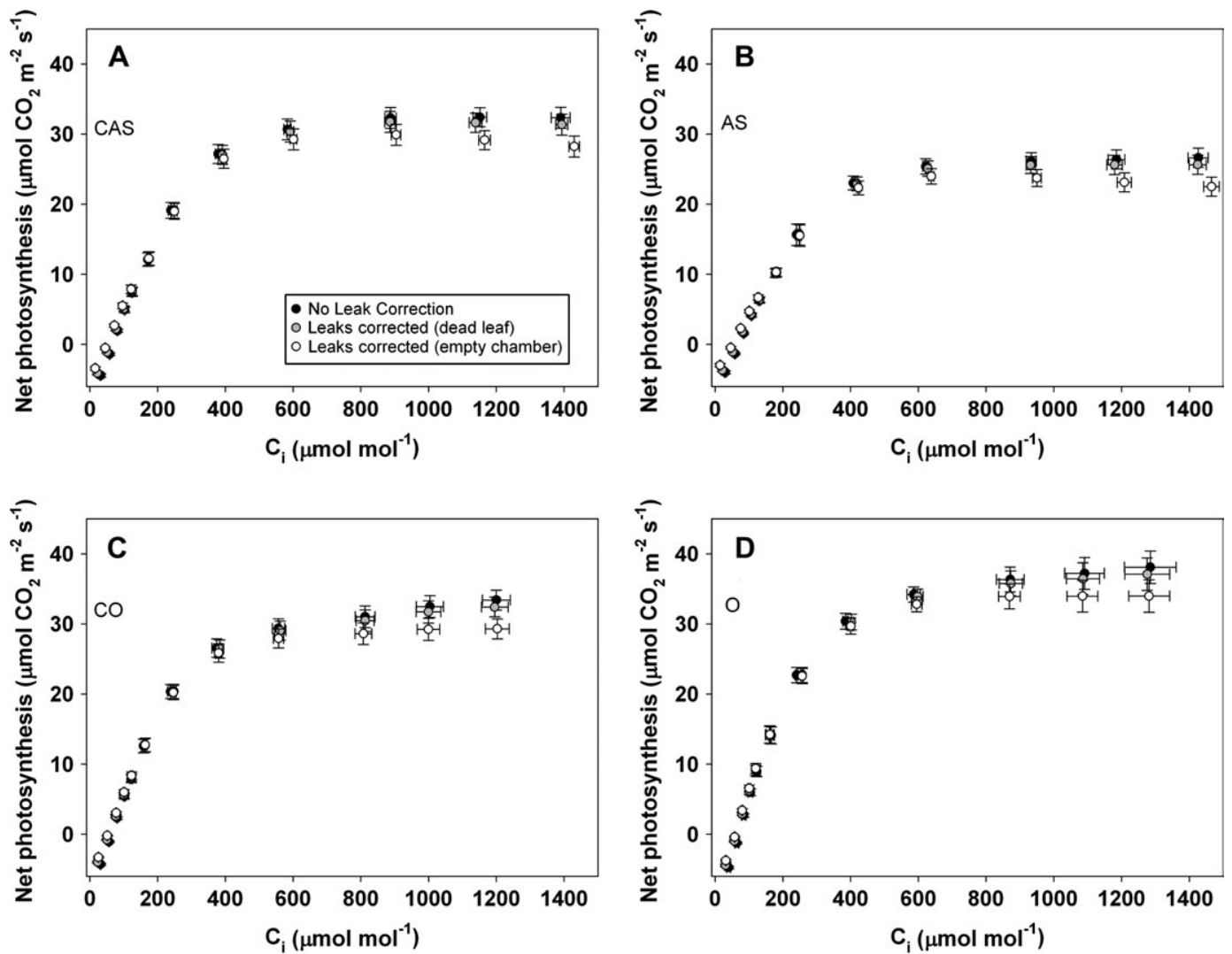

Fig. 5. The response of $A$ to substomatal $\mathrm{CO}_{2}$ concentration, $\mathrm{C}_{\mathrm{i}}$, in tobacco CAS (A), AS (B), $\mathrm{CO}(\mathrm{C})$, and $\mathrm{O}$ (D) without correction (filled circles) or after correction for leaks obtained with a dead leaf (grey circles) or an empty chamber (open circles). Values are means \pm SE of six replicates per genotype.

Table 1. Photosynthetic parameterization from A- $C_{i}$ curves with no correction for leaks (NC), or corrected for the leaks tested using a dead leaf of tobacco $(C D)$ or an empty chamber $(C E)$

All parameters are the average \pm SE of six replicates, and expressed in $\mu \mathrm{mol} \mathrm{m}{ }^{-2} \mathrm{~s}^{-1} . \% \mathrm{CD}$ and $\% \mathrm{EC}$ are the percentage variation for each parameter as compared with the non-corrected curve.

\begin{tabular}{|c|c|c|c|c|c|c|}
\hline & Genotype & $\mathrm{NC}$ & $\mathrm{CD}$ & $\mathrm{CE}$ & $\% \mathrm{CD}$ & $\% \mathrm{CE}$ \\
\hline \multirow{5}{*}{$V_{\text {cmax_Ci }}$} & CAS & $108.6 \pm 5.9$ & $96.7 \pm 5.1$ & $89.4 \pm 5.0$ & $10.9 *$ & $17.7 * *$ \\
\hline & AS & $89.2 \pm 6.8$ & $80.2 \pm 6.1$ & $73.3 \pm 5.1$ & $10.1^{*}$ & $17.6^{* *}$ \\
\hline & $\mathrm{CO}$ & $113.4 \pm 7.1$ & $101.9 \pm 5.9$ & $99.1 \pm 5.8$ & 9.9 & 12.5 \\
\hline & $\mathrm{O}$ & $128.4 \pm 6.4$ & $115.6 \pm 6.2$ & $111.4 \pm 6.3$ & $9.7 *$ & $13.4 * *$ \\
\hline & Average & & & & $10.1^{*}$ & $15.3 * *$ \\
\hline \multirow{5}{*}{$J_{\text {max }_{-} \mathrm{Ci}}$} & CAS & $169.2 \pm 7.6$ & $155.3 \pm 6.8$ & $147.3 \pm 8.0$ & $8.2^{*}$ & $12.1^{* *}$ \\
\hline & AS & $141.5 \pm 6.9$ & $142.4 \pm 5.6$ & $123.7 \pm 6.3$ & 4.0 & $12.1 * *$ \\
\hline & $\mathrm{CO}$ & $165.7 \pm 7.9$ & $155.9 \pm 7.9$ & $149.4 \pm 8.1$ & 6.0 & 10.0 \\
\hline & $\mathrm{O}$ & $191.8 \pm 6.4$ & $184.4 \pm 6.6$ & $183.1 \pm 4.7$ & 3.7 & 6.5 \\
\hline & Average & & & & 5.5 & $10.1^{* *}$ \\
\hline \multirow{5}{*}{$V_{\mathrm{TPU} \_\mathrm{Ci}}$} & CAS & $11.4 \pm 0.5$ & $10.4 \pm 0.5$ & $9.5 \pm 0.5$ & $8.1^{*}$ & $16.6^{* *}$ \\
\hline & AS & $9.4 \pm 0.6$ & $8.7 \pm 0.5$ & $7.3 \pm 0.5$ & $6.6^{*}$ & $23.0^{* *}$ \\
\hline & $\mathrm{CO}$ & $10.9 \pm 0.5$ & $10.3 \pm 0.4$ & $9.8 \pm 0.5$ & 5.6 & $14.5^{* *}$ \\
\hline & $\mathrm{O}$ & $11.7 \pm 0.3$ & $11.4 \pm 0.4$ & $11.5 \pm 0.6$ & 2.9 & $11.3 * *$ \\
\hline & Average & & & & 5.8 & 16.3 \\
\hline \multirow[t]{5}{*}{$\mathrm{R}_{l}$} & CAS & $3.0 \pm 0.3$ & $1.7 \pm 0.2$ & $0.4 \pm 0.2$ & $45.7 * *$ & $87.7 * *$ \\
\hline & AS & $2.6 \pm 0.4$ & $1.6 \pm 0.3$ & $0.4 \pm 0.2$ & $41.6^{* *}$ & $89.9 * *$ \\
\hline & $\mathrm{CO}$ & $3.0 \pm 0.2$ & $1.8 \pm 0.2$ & $1.3 \pm 0.1$ & $38.1^{* *}$ & $56.9 * *$ \\
\hline & $\mathrm{O}$ & $3.3 \pm 0.2$ & $2.7 \pm 0.3$ & $2.2 \pm 0.3$ & $27.1 * *$ & $32.8^{* *}$ \\
\hline & Average & & & & $38.1 * *$ & $66.8^{* *}$ \\
\hline
\end{tabular}

* Average values in $\mathrm{CD}$ represent an intermediate group between $\mathrm{NC}$ and $\mathrm{CE}$.

** Average values in CD or CE represent a group fully separated from NC. 
this parameter accurately even if a proper estimate of leaks is carried out. It has been already suggested that $R_{1}$ estimates using parameterization of the Farquhar et al. (1980) model of photosynthesis are not reliable, and many authors prefer other methods to assess $R_{1}$ (Brooks and Farquhar, 1985). Because other gas exchange methods, such as that described by Brooks and Farquhar (1985), are affected not only by leakage but also by many other technical problems (Galmes et al., 2006), only methods to measure $R_{1}$ with labelled compounds (e.g. Haupt-Herting et al., 2001; Pinelli and Loreto, 2003) can be much more accurate and error-free in determining the true respiratory out-flux of $\mathrm{CO}_{2}$ in illuminated leaves. The differences in $V_{\text {c,max_Ci }}$ were also significant $(10 \%)$, which may be considered as an important bias. Leakage generally did not significantly affect estimations of $J_{\text {max_Ci }}$ or $V_{\mathrm{TPU} \_\mathrm{Ci}}$ (Table 1). Corrections using leaks estimated on an empty chamber, as done in some studies (Bernacchi et al., 2001, 2002; Manter and Kerrigan, 2004), would lead to much larger, unrealistic differences in all these parameters (Table 1).

It is noticeable that the percentage error due to ignoring the effects of leakage did not depend on the photosynthetic rates. For instance, at ambient $\mathrm{CO}_{2}$ concentration, $A_{\mathrm{N}}$ in AS plants was $17 \mu \mathrm{mol} \mathrm{CO}_{2} \mathrm{~m}^{-2} \mathrm{~s}^{-1}$, while in
$\mathrm{O}$ plants it reached $22 \mu \mathrm{mol} \mathrm{CO}_{2} \mathrm{~m}^{-2} \mathrm{~s}^{-1}$. However, the percentage error for $V_{\mathrm{c}, \text { max_Ci }}$ and $J_{\text {max_Ci }}$ was identical. This may suggest that a relative comparison of species or treatments would be possible even without taking leakage into account. Nevertheless, the ranges of photosynthesis compared here were relatively small. It is suggested that, for larger differences in photosynthesis (e.g. when photosynthesis is reduced by any severe stress), the percentage error caused by ignoring leaks would differ between treatments, since the same absolute leak rate will represent a much larger percentage error in $A_{\mathrm{N}}$ if the latter is largely reduced. On the other hand, when $A_{\mathrm{N}}-\mathrm{C}_{\mathrm{i}}$ curves are performed to parameterize leaf or canopy models for prediction of photosynthesis (Walcroft et al., 1997; Cai and Dang, 2002; Medlyn et al., 2002a, b; Diaz-Espejo et al., 2006), the accuracy in the estimations of these parameters would be more important.

\section{Leakage effects on photosynthesis parameterization from $\mathrm{A}-\mathrm{C}_{c}$ curves}

As already discussed (Flexas et al., 2006), A-C $\mathrm{C}_{\mathrm{i}}$ curves differed greatly from $A-\mathrm{C}_{\mathrm{c}}$ curves (Fig. 6). $V_{\mathrm{c}, \text { max_Ci }}$ was 20-40\% larger than $V_{\mathrm{c} \text {,max_Cc }}$ depending on the genotype (Tables 1 and 2). $J_{\text {max_Cc }}$ was less affected, yet it was $10 \%$
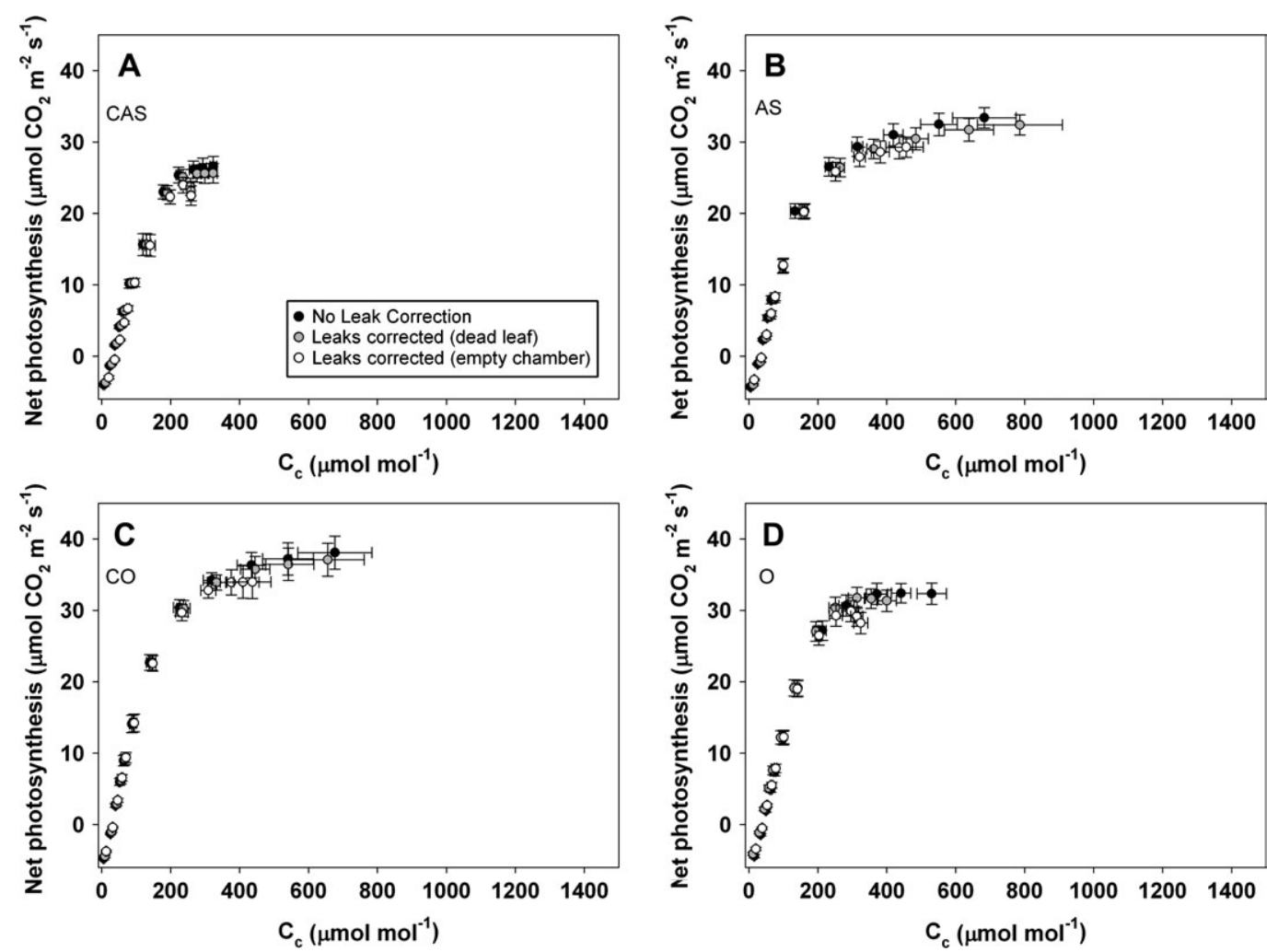

Fig. 6. The response of $A$ to chloroplastic $\mathrm{CO}_{2}$ concentration, $\mathrm{C}_{\mathrm{c}}$, in tobacco CAS (A), AS (B), CO (C), and O (D) without correction (filled circles) or after correction for leaks obtained with a dead leaf (grey circles), or an empty chamber (open circles). Values are means \pm SE of six replicates per genotype. 
Table 2. Photosynthetic parameterization from $\mathrm{A}-C_{c}$ curves with no correction for leaks $(N C)$, or corrected for the leaks tested using a dead leaf of tobacco (CD) or an empty chamber (CE)

All parameters are the average \pm SE of six replicates, and expressed in $\mu \mathrm{mol} \mathrm{m} \mathrm{m}^{-2} \mathrm{~s}^{-1} . \% \mathrm{CD}$ and \%EC are the percentage variation for each parameter as compared with the non-corrected curve (all values were non-significant).

\begin{tabular}{lllllrr}
\hline & Genotype & NC & CD & CE & $\%$ CD & $\% \mathrm{CE}$ \\
\hline$V_{\text {cmax_Cc }}$ CAS & $147.2 \pm 7.4$ & $143.8 \pm 7.3$ & $141.2 \pm 7.2$ & 2.3 & 4.1 \\
& AS & $150.7 \pm 9.6$ & $146.3 \pm 9.9$ & $142.7 \pm 9.4$ & 2.9 & 5.3 \\
& CO & $146.4 \pm 5.9$ & $141.2 \pm 6.5$ & $140.9 \pm 5.9$ & 3.5 & 3.8 \\
& O & $170.0 \pm 6.7$ & $166.5 \pm 6.6$ & $164.6 \pm 6.2$ & 2.1 & 3.2 \\
& Average & & & & 2.7 & 4.1 \\
$\mathrm{~J}_{\text {max_Cc }}$ & CAS & $182.7 \pm 6.7$ & $182.6 \pm 6.6$ & $183.3 \pm 6.3$ & 0.0 & -0.3 \\
& AS & $157.0 \pm 7.4$ & $157.2 \pm 7.4$ & $159.0 \pm 6.5$ & -0.1 & -1.2 \\
CO & $159.2 \pm 5.0$ & $159.2 \pm 5.0$ & $159.5 \pm 5.1$ & 0.0 & 0.2 \\
& O & $181.0 \pm 3.9$ & $181.0 \pm 3.8$ & $181.0 \pm 3.9$ & 0.0 & 0.0 \\
& Average & & & & 0.0 & -0.4 \\
\hline
\end{tabular}

larger on a $\mathrm{C}_{\mathrm{c}}$ basis for AS plants. There is now ample consensus that photosynthetic parameterization must be done on a $\mathrm{C}_{\mathrm{c}}$ rather than on a $\mathrm{C}_{\mathrm{i}}$ basis, since they both differ greatly in plants and the former more closely represents the $\mathrm{CO}_{2}$ concentration at the sites of carboxylation (Bernacchi et al., 2002; Ethier and Livingston, 2004; Manter and Kerrigan, 2004; Grassi and Magnani, 2005; Flexas et al., 2006). This may be particularly important under conditions where the ratio $\mathrm{C}_{\mathrm{i}} / \mathrm{C}_{\mathrm{c}}$ is changing, such as under water or salt stress (Centritto et al., 2003; Flexas et al., 2004).

Clearly, the effects of leakage on $A-\mathrm{C}_{\mathrm{c}}$ curves (Fig. 6) and their parameterization (Table 2) were much lower than for $A-C_{\mathrm{i}}$ curves, and for the present data they were non-significant. This is because leakage affects $A$ and $\mathrm{C}_{\mathrm{i}}$ in opposite ways, while it affects $A$ and $\mathrm{C}_{\mathrm{c}}$ in the same direction. For instance, in a CAS plant at the lowest end of $C_{a}$ (i.e. $100 \mu \mathrm{mol} \mathrm{mol}^{-1}$ air, where the percentage error in $A$ is larger), $A$ without correcting for leaks was $2 \mu \mathrm{mol}$ $\mathrm{CO}_{2} \mathrm{~m}^{-2} \mathrm{~s}^{-1}$, while $\mathrm{C}_{\mathrm{i}}$ was $80 \mu \mathrm{mol} \mathrm{mol} \mathrm{m}^{-1}$ air. Correcting for leaks resulted in a $26 \%$ increase in $A$ with a $14 \%$ decrease in $\mathrm{C}_{\mathrm{i}}$. In this plant, the linear rate of electron transport was $97 \mu \mathrm{mol} \mathrm{e} \mathrm{e}^{-2} \mathrm{~s}^{-1}$. The estimated $\mathrm{C}_{\mathrm{c}}$ without correcting for leaks was $64 \mu \mathrm{mol} \mathrm{mol}{ }^{-1}$ air, but it increased by $7 \%$ when leaks were taken into account. Therefore, since both $A$ and $\mathrm{C}_{\mathrm{c}}$ are affected in the same way (although to a somewhat different extent), the effects of leakage on $V_{\mathrm{c}, \text { max_Cc }}$ have less impact.

\section{Concluding remarks}

$\mathrm{CO}_{2}$ leakage occurs when using small IRGA chambers, such as those of the Li-6400 (LI-COR Inc., Lincoln, NE, USA) and most other modern portable systems, especially when performing $A-\mathrm{C}_{\mathrm{i}}$ curves. The present results suggest that most leakage takes place at the interface between the two sealing gaskets of the clamping chamber, and not through the chamber gaskets, as previously suggested. Attempting to equilibrate inside and outside $\mathrm{CO}_{2}$ concentrations has proven difficult. The presence of leaks induces errors in the measurement of both $A$ and $\mathrm{C}_{\mathrm{i}}$, impairing the correct parameterization of photosynthesis following the Farquhar model. However, the magnitude of these errors is considerably reduced when $A-\mathrm{C}_{\mathrm{c}}$ curves are used for parameterization. Therefore, if $A-\mathrm{C}_{\mathrm{c}}$ curves are obtained, it may not be necessary to estimate the magnitude of leakage for most applications. If increasing accuracy by applying a correction is desired, the simplest method would be to use photosynthetically inert leaves after placing them in boiling water.

\section{Acknowledgements}

This work was partly supported by grants AGL2005-06927-CO201/AGR, BFI2002-00772, and BFU2005-03102/BFI (Plan Nacional, Spain). MR-C and AD-E were beneficiaries of the Programa Ramón y Cajal (M.E.C.)

\section{References}

Bernacchi CJ, Portis AR, Nakano H, von Caemmerer S, Long SP. 2002. Temperature response of mesophyll conductance. Implications for the determination of Rubisco enzyme kinetics and for limitations to photosynthesis in vivo. Plant Physiology 130, 1992-1998.

Bernacchi CJ, Singsaas EL, Pimentel C, Portis AR, Long SP. 2001. Improved temperature response functions for models of Rubisco-limited photosynthesis. Plant, Cell and Environment 24, 253-259.

Bota J, Medrano H, Flexas J. 2004. Is photosynthesis limited by decreased Rubisco activity and RuBP content under progressive water stress? New Phytologist 162, 671-681.

Boyer JS, Wong SC, Farquhar GD. 1997. $\mathrm{CO}_{2}$ and water vapour exchange across leaf cuticle (epidermis) at various water potentials. Plant Physiology 114, 185-191.

Brooks A, Farquhar GD. 1985. Effect of temperature on the $\mathrm{CO}_{2} /$ $\mathrm{O}_{2}$ specificity of ribulose-1,5-bisphosphate carboxylase/oxygenase and the rate of respiration in the light-estimate from gasexchange measurements on spinach. Planta 165, 397-406.

Buckley TN, Farquhar GD, Mott KA. 1997. Qualitative effects of patchy stomatal conductance distribution features on gasexchange calculations. Plant, Cell and Environment 20, 867-880.

Cai TB, Dang QL. 2002. Effects of soil temperature on parameters of a coupled photosynthesis-stomatal conductance model. Tree Physiology 22, 819-827.

Centritto M, Loreto F, Chartzoulakis K. 2003. The use of low $\left[\mathrm{CO}_{2}\right]$ to estimate diffusional and non-diffusional limitations of photosynthetic capacity of salt-stressed olive samplings. Plant, Cell and Environment 26, 585-594.

Díaz-Espejo A, Walcroft AS, Fernández JE, Hafidi B, Palomo MJ, Girón IF. 2006. Modelling photosynthesis in olive leaves under drought conditions. Tree Physiology 26, 1445-1456.

Epron D, Godard G, Cornic G, Genty B. 1995. Limitation of net $\mathrm{CO}_{2}$ assimilation rate by internal resistances to $\mathrm{CO}_{2}$ transfer in the leaves of two tree species (Fagus sylvatica and Castanea sativa Mill.) Plant, Cell and Environment 18, 43-51. 
Ethier GH, Livingston NJ. 2004. On the need to incorporate sensitivity to $\mathrm{CO}_{2}$ transfer conductance into the Farquhar-von Caemmerer-Berry leaf photosynthesis model. Plant, Cell and Environment 27, 137-153.

Evans JR, Sharkey TD, Berry JA, Farquhar GD. 1986. Carbon isotope discrimination measured concurrently with gas exchange to investigate $\mathrm{CO}_{2}$ diffusion in leaves of higher plants. Australian Journal of Plant Physiology 13, 281-292.

Farquhar GD, von Caemmerer S, Berry JA. 1980. A biochemical model of photosynthetic $\mathrm{CO}_{2}$ assimilation in leaves of $\mathrm{C}_{3}$ species. Planta 149, 78-90.

Flexas J, Bota J, Escalona JM, Sampol B, Medrano H. 2002. Effects of drought on photosynthesis in grapevines under field conditions: an evaluation of stomatal and mesophyll limitations. Functional Plant Biology 29, 461-471.

Flexas J, Bota J, Loreto F, Cornic G, Sharkey TD. 2004. Diffusive and metabolic limitations to photosynthesis under drought and salinity in C3 plants. Plant Biology 6, 269-279.

Flexas J, Ribas-Carbó M, Hanson DT, Bota J, Otto B, Cifre J, McDowell N, Medrano H, Kaldenhoff R. 2006. Tobacco aquaporin NtAQP1 is involved in mesophyll conductance to $\mathrm{CO}_{2}$ in vivo. The Plant Journal 48, 427-439.

Galmés J, Medrano H, Flexas J. 2006. Acclimation of Rubisco specificity factor to drought in tobacco: discrepancies between in vitro and in vivo estimations. Journal of Experimental Botany 57, 3659-3667.

Genty B, Briantais JM, Baker NR. 1989. The relationship between the quantum yield of photosynthetic electron transport and quenching of chlorophyll fluorescence. Biochimica et Biophysica Acta 990, 87-92.

Grassi G, Magnani F. 2005. Stomatal, mesophyll conductance and biochemical limitations to photosynthesis as affected by drought and leaf ontogeny in ash and oak trees. Plant, Cell and Environment 28, 834-849.

Harley PC, Loreto F, Di Marco G, Sharkey TD. 1992. Theoretical considerations when estimating the mesophyll conductance to $\mathrm{CO}_{2}$ flux by the analysis of the response of photosynthesis to $\mathrm{CO}_{2}$. Plant Physiology 98, 1429-1436.

Haupt-Herting S, Klug K, Fock H. 2001. A new approach to measure gross $\mathrm{CO}_{2}$ fluxes in leaves. Gross $\mathrm{CO}_{2}$ assimilation, photorespiration, and mitochondrial respiration in the light in tomato under drought stress. Plant Physiology 126, 388-396.

Jahnke S, Krewitt M. 2002. Atmospheric $\mathrm{CO}_{2}$ concentration may directly affect leaf respiration measurement in tobacco, but not respiration itself. Plant, Cell and Environment 25, 641-651.

Jahnke S, Pieruschka R. 2006. Air pressure in clamp-on leaf chambers: a neglected issue in gas exchange measurements. Journal of Experimental Botany 57, 2553-2561.

Li-COR. 2005. Using the Li-6400 portable gas exchange system. Version 5. Lincoln, NE: LI-COR Biosciences Inc.

Long SP, Bernacchi CJ. 2003. Gas exchange measurements, what can they tell us about the underlying limitations to photosynthesis? Procedures and sources of error. Journal of Experimental Botany 54, 2393-2401.

Long SP, Hällgren J-E. 1993. Measurement of $\mathrm{CO}_{2}$ assimilation by plants in the field and laboratory. In: Hall DO, Scurlock JMO, Bolhar-Nordenkampf HR, Leegood RC, Long SP, eds. Photosynthesis and productivity in a changing environment: a field and laboratory manual. London: Chapman and Hall, 129-167.

Loreto F, Harley PC, Di Marco G, Sharkey TD. 1992. Estimation of mesophyll conductance to $\mathrm{CO}_{2}$ flux by three different methods. Plant Physiology 98, 1437-1443.
Manter DK, Kerrigan J. 2004. A/ $\mathrm{C}_{\mathrm{i}}$ curve analysis across a range of woody plant species: influence of regression analysis parameters and mesophyll conductance. Journal of Experimental Botany 55, 2581-2588.

Medlyn BE, Loustau D, Delzon S. 2002. Temperature response of parameters of a biochemically based model of photosynthesis. I. Seasonal changes in mature maritime pine (Pinus pinaster Ait. Plant, Cell and Environment 25, 1155-1165.

Medlyn BE, Dreyer E, Ellsworth D, et al. 2002. Temperature response of parameters of a biochemically based model of photosynthesis. II. A review of experimental data. Plant, Cell and Environment 25, 1167-1179.

Pieruschka R, Schurr U, Jahnke S. 2005. Lateral gas diffusion inside leaves. Journal of Experimental Botany 413, 857-864.

Pinelli P, Loreto F. 2003. $\left(\mathrm{CO}_{2}\right)-\mathrm{C}^{12}$ emission from different metabolic pathways measured in illuminated and darkened $\mathrm{C}_{3}$ and $\mathrm{C}_{4}$ leaves at low, atmospheric and elevated $\mathrm{CO}_{2}$ concentration. Journal of Experimental Botany 54, 1761-1769.

Pons TL, Welschen RAM. 2002. Overestimation of respiration rates in commercially available clamp-on leaf chambers. Complications with measurement of net photosynthesis. Plant, Cell and Environment 25, 1367-1372.

Sabate S, Gracia CA, Sanchez A. 2002. Likely effects of climate change on growth of Quercus ilex, Pinus halepensis, Pinus pinaster, Pinus sylvestris and Fagus sylvatica forests in the Mediterranean region. Forest Ecology and Management 162, 23-37.

Sampol B, Bota J, Riera D, Medrano H, Flexas J. 2003. Analysis of the virus-induced inhibition of photosynthesis in malmsey grapevines. New Phytologist 160, 403-412.

Schreiber U, Bilger W, Hormann H, Neubauer C. 1998. Chlorophyll fluorescence as a diagnostic tool: basics and some aspects of practical rellevance. In: Raghavendra AS, ed. Photosynthesis. A comprehensive treatise. Cambridge: Cambridge University Press, 320-336.

Schultz HR. 2003. Extension of a Farquhar model for limitations of leaf photosynthesis induced by light environment, phenology and leaf age in grapevines (Vitis vinifera L. cvv. White Riesling and Zinfandel). Functional Plant Biology 30, 673-687.

Siefritz F, Tyree MT, Lovisolo C, Schubert A, Kaldenhoff R. 2002. PIP1 plasma membrane aquaporins in tobacco: from cellular effects to function in plants. The Plant Cell 14, 869-876.

Terashima I. 1992. Anatomy of non-uniform leaf photosynthesis. Photosynthesis Research 31, 195-212.

Terashima I, Ono K. 2002. Effects of $\mathrm{HgCl}_{2}$ on $\mathrm{CO}_{2}$ dependence of leaf photosynthesis: evidence indicating involvement of aquaporins in $\mathrm{CO}_{2}$ diffusion across the plasma membrane. Plant and Cell Physiology 43, 70-78.

Tyree MT, Wilmot TR. 1990. Errors in the calculation of evaporation and leaf conductance in steady-state porometry-the importance of accurate measurement of leaf temperature. Canadian Journal of Forest Research 20, 1031-1035.

Uehlein N, Lovisolo C, Siefritz F, Kaldenhoff R. 2003. The tobacco aquaporin NtAQP1 is a membrane $\mathrm{CO}_{2}$ transporter with physiological functions. Nature 425, 734-737.

Valentini R, Epron D, De Angelis P, Matteucci G, Dreyer E. 1995. In situ estimation of net $\mathrm{CO}_{2}$ assimilation, photosynthetic electron flow and photorespiration in Turkey oak (Quercus cerris L.) leaves: diurnal cycles under different levels of water supply. Plant, Cell and Environment 18, 631-640.

Verhoef A. 1997. The effect of temperature differences between porometer head and leaf surface on stomatal conductance measurements. Plant, Cell and Environment 20, 641-646.

Walcroft AS, Whitehead D, Silvester WB, Kelliher FM. 1997. The response of photosynthetic model parameters to temperature 
and nitrogen concentration in Pinus radiata D. Don. Plant, Cell and Environment 20, 1338-1348.

Warren CR. 2004. The photosynthetic limitation posed by internal conductance to $\mathrm{CO}_{2}$ movement is increased by nutrient supply. Journal of Experimental Botany 55, 2313-2321.

Warren CR, Livingston NJ, Turpin DH. 2004. Water stress decreases the transfer conductance of Douglas-fir (Pseudotsuga menziensii) seedlings. Tree Physiology 24, 971-979.

Wilson KB, Baldocchi DD, Hanson PJ. 2000. Quantifying stomatal and non-stomatal limitations to carbon assimilation resulting from leaf aging and drought in mature deciduous tree species. Tree Physiology 20, 787-797.
Woodward I, Smith TM, Emanuel WR. 1995. A global land primary productivity and phytogeography model. Global Biochemical Cycles 9, 471-490.

Xu L, Baldocchi DD. 2003. Seasonal trends in photosynthetic parameters and stomatal conductance of blue oak (Quercus douglasii) under prolonged summer drought and high temperature. Tree Physiology 23, 865-877.

Zhou YH, Yu JQ, Huang LF, Nogues S. 2004. The relationship between $\mathrm{CO}_{2}$ assimilation, photosynthetic electron transport and water-water cycle in chill-exposed cucumber leaves under low light and subsequent recovery. Plant, Cell and Environment 27, 1503-1514. 